\title{
Salmonicultura 2.0 en Chile: Una mirada desde la gobernanza ambiental ${ }^{*}$
}

\author{
Vallejos-Romero, Arturo** \\ Oyarzún Gutiérrez, Ivone ${ }^{* * *}$ \\ Garrido Castillo, Jaime****
}

\begin{abstract}
Resumen
Dado el contexto social y organizacional de los conflictos producidos por la salmonicultura en la región de Los Lagos (Chile), este artículo pretende aportar a la implementación de un nuevo modelo de gestión para la salmonicultura 2.0 desde la gobernanza ambiental. En función de la observación de la puesta en práctica de la denominada industria 2.0, la investigación se propuso indagar empíricamente (entrevistas semiestructuradas) las percepciones de los actores clave del sector, respecto a las categorías centrales de la gobernanza ambiental: sustentabilidad, información pública y participación ciudadana. Los principales resultados del trabajo señalan que el desarrollo e institucionalización de los ejes mencionados es absolutamente insuficiente. El espíritu que mueve la nueva forma dada a la salmonicultura no estaría haciendo suyos los lineamientos de la gobernanza ambiental, por lo que este nuevo modelo podría fracasar. Es decir, no se percibe el principio de sustentabilidad en la salmonicultura 2.0 debido a su lenta recuperación ambiental y su actual priorización económica y social. En función de ello, se propone a partir de estas visiones el despliegue de estrategias y redes como una fuente de articulación para el modelo de gobernanza y de activación de nuevos rubros económicos.
\end{abstract}

Palabras clave: Gobernanza, participación, sustentabilidad, comunicación.

\section{Recibido: 30-03-12. Aceptado: 07-02-14}

* El artículo es producto del Proyecto Fondecyt 1120554 financiado por CONICYT de Chile.

** Doctor, Profesor e investigador a tiempo completo del Núcleo de Investigación en Ciencias Sociales y Humanidades de la Universidad de La Frontera, Temuco, Chile, e-mail: arturo.vallejos @ufrontera.cl

*** Socióloga, Investigadora de la Universidad de La Frontera, e-mail: i.oyarzun.gutierrez @gmail.com

**** Doctor, Profesor a tiempo completo de la Universidad de La Frontera, e-mail: jame.garrido.c @ufrontera.cl 


\title{
The Salmon Industry 2.0 in Chile: A Perspective from the Viewpoint of Environmental Governance
}

\begin{abstract}
Given the social and organizational context of the conflicts produced by the salmon industry in the Los Lagos region (Chile), this article intends to contribute to implementing a new administrative model for the salmon industry 2.0 from the perspective of environmental governance. Observing the implementation of the so-called industry 2.0, this research proposed an empirical investigation (semi-structured interviews) of the perceptions of key actors in the sector with regard to the central categories of environmental governance: sustainability, public information and citizen participation. The main results of this work indicate that the development and institutionalization of the aforementioned axis are absolutely insufficient. The spirit that moves the new form given to salmon culture would not be making the guidelines of environmental governance its own, so this new model could fail. That is, the principle of sustainability is not perceived in salmon culture 2.0 due to its slow environmental recovery and its current economic and social prioritization. This study proposes the presentation of networks and strategies as a source of articulation for the governance model and the activation of new economic fields.
\end{abstract}

Key words: Governance, participation, sustainability, communication.

\section{Introducción}

El modelo económico asumido por Chile desde mediados de la década de los ochenta del siglo pasado, se ha basado fundamentalmente en una lógica productiva y expansiva, cuyo fundamento es la extracción intensiva y exportación de recursos naturales. Desde la década de 1990, el modelo económico comienza a exhibir destacables cifras positivas, siendo la industria del salmón uno de sus "productos estrellas", cuestión particularmente relevante, dado que en el contexto de los mercados internacionales, Chile es el único país no desarrollado que produce salmonideos en cantidades importantes. Las cifras son contundentes: entre 1990 y 2008 el país concentró el $31 \%$ del cultivo a nivel mundial. No obstante sus grandes logros, la industria del salmón presenta, a nivel local como internacional, un conjunto de críticas y cuestionamientos a su modelo de gestión, que se traducen en la práctica en acusaciones laborales y medioambientales (Furci, 2008; Pinto, 2008).

La salmonicultura en Chile tiene sus comienzos en el siglo pasado, siendo 1905 el año en el cual se realiza la primera introducción de salmones, especie exótica, en aguas chilenas. En 1974, la actividad se torna en uno de los polos mayor importancia, siendo uno de los ejes clave para el crecimiento económico que se comienza a gestar en el país, afianzado en un modelo neoliberal que se fundamenta en la transformación del capital natural en capital financiero (Centro de Estudios Miguel Enríquez (CEME), 2007). En su período de consolidación, que va desde mediados de la década de 1970 a la de 1990, la salmonicultura se caracterizó por un gran número de concesiones acuícolas privadas, cuyo mecanismo se tradujo en que cada empresa explotaba 
Salmonicultura 2.0 en Chile: Una mirada desde la gobernanza ambiental Vallejos-Romero, Arturo; Oyarzún Gutiérrez, Ivone y Garrido Castillo, Jaime

su propio espacio marítimo. De 1990 en adelante, el sector comienza a vivir su más importante momento de auge, expresado en un aumento de sus exportaciones que al año 2007 muestran una tasa de crecimiento anual de aproximadamente un $20 \%$. De esta manera, la lógica de producción llevó a que en el año 2004 la industria del salmón llegara a su mejor momento a nivel internacional, compitiendo con el principal exportador del mundo; Noruega, con una participación de mercado mundial que bordeó el $38 \%$, cifra exitosa si para el año 1992 correspondía sólo a un 14\% (Pinto, 2008).

El crecimiento exponencial de la industria de los salmones, sólo se explica en la conjugación de un conjunto de factores. Primero, características geográficas que ofrecen ventajas comparativas para el cultivo, como la disposición del borde costero junto a la calidad del recurso de agua definido por su pureza, temperatura y corrientes marítimas. Segundo, la inversión privada. Tercero, la estacionalidad inversa a la del hemisferio norte donde se concentran los mercados de consumo más importantes. Cuarto, abundante mano de obra y de bajo costo relativo. Por último, la disposición abundante y de bajo costo de la harina de pescado, elemento esencial de la dieta de los salmones (Pinto, 2008:04). A nivel nacional, la industria del salmón se posicionó como la principal actividad económica, focalizada su alta producción en la región de Los Lagos.

Para dimensionar el auge de este eje, el sector de pesca extractiva y acuicultura exportó U\$3.669 en el 2006 , correspondiéndole al salmón un $67,3 \%$ de las exportaciones pesqueras totales, destinadas principalmente a Estados
Unidos, Japón y la Unión Europea (Igor y Díaz, 2007). Es por ello, que económicamente, este sector tomó gran importancia, especialmente porque este producto se ancla en las regiones del sur de Chile, llegando el PIB regional para la región de Los Lagos a un $11,5 \%$ en la década del noventa del siglo pasado (Claude y Oporto, 2000).

Antes de la crisis provocada por la Anemia Infecciosa del Salmón (en adelante ISA), enfermedad contagiosa y mortal que afecta exclusivamente al salmón del atlántico y que entre las prácticas de cultivo que propician e inciden en la expansión del virus destacan las altas densidades de cultivo permitidas en Chile (Kilogramos de peces por balsa jaula); el número de balsas jaulas por centro de cultivo; la cercanía entre un centro de cultivo y otro; y la ausencia de una normativa que instale la rotación y descanso de sitios (fallowing) como práctica obligatoria (Carreño, 2010). La productividad del sector en el año 2004 llegó a representar el 30\% aproximado de la producción global del salmón y el año 2003, la Región de Los Lagos alcanzó el $84 \%$ de la producción a nivel nacional.

En el año 2007, la industria del salmón generó alrededor de 50 mil empleos directos e indirectos en plantas procesadoras, transporte y centros de cultivo (Claude y Oporto, 2000). Pero esta intensa lógica de producción tuvo sus consecuencias, produciendo una serie de efectos medioambientales, sociales y económicos negativos que combinados con el impacto del virus ISA, provocó una fuerte crisis que se tradujo en el cierre del $50 \%$ de los centros productivos de salmón, registrándose con ello, la pérdida de más 
de 25.000 puestos de trabajos directos y más de 40.000 empleos indirectos.

En el ámbito social y laboral, la industria del salmón ha generado impactos intensos en la estructura funcional y social en su zona de producción, especialmente en la región de Los Lagos, y en particular la Isla de Chiloé, que pasa de actividades agrícolas y pesca artesanal a albergar una actividad que no ha impactado positivamente en sus condiciones de pobreza. Los datos de la Encuesta de Caracterización Socioeconómica (CASEN) $2006,{ }^{1}$ informan que para ese año la pobreza alcanzó un $8,7 \%$ de la población, subiendo el año 2009 al 12, 4\%. Los principales puntos críticos están relacionados con a) personas ahogadas en los centros de cultivo; b) por enfermedades que sufren las mujeres ( $91 \%$ de la fuerza laboral) al estar expuestas por largo tiempo al frío y al ruido; c) un trabajo inestable y sus sueldos variables; d) falta de control sobre la profundidad real en que trabajan los buzos, los cuales sufren graves daños neurológicos; e) una sindicalización baja (13 al 15\%); f) altas multas por falta de higiene y baja seguridad, y g) una alta subcontratación. En términos generales, una precarización del empleo, donde los beneficios son desigualmente distribuidos y donde los trabajadores reciben menos de 200.000 pesos mensuales, ubicando sus hogares cerca de la línea de la pobreza y en los primeros deciles de la distribución de ingreso regional (Pinto, 2007).
Los impactos ambientales generados por el sector salmonideo están relacionados con la tasa de conversión, es decir, la cantidad de peces requeridos para producir un kilo de salmón, el uso indiscriminado de químicos y antibióticos, la gran cantidad de desechos que genera el alimento no ingerido, las excretas de los peces, el escape de especímenes y el precario manejo sanitario que favorece la emergencia de enfermedades y su propagación (Pinto, 2008). Esta arista es la que ha sido determinante en el cambio hacia un manejo sustentable de la salmonicultura, pues, para producir un kilo de salmón en Chile, se requieren más de ocho kilos de peces como sardinas, jureles, anchovetas, entre otros. Esta situación tiene en sí un elevado costo ecológico y social, por cuanto producir un pez como el salmón a costa de otras especies que presentan valores alimenticios similares, es cuestionable desde el punto de vista de la seguridad alimentaria mundial (Pinto, 2008).

De esta manera, la Ley de Pesca y Acuicultura (Gobierno de Chile, 1991) que regula la salmonicultura, fue modificada tomando en cuenta las consecuencias de la crisis, y por tanto, incluyendo parámetros para que la gestión fuese sustentable en el tiempo. La Ley 20.434 modificada en abril de 2010 (Congreso Nacional de Chile, 2010), contempla cambios referidos al a) Manejo sanitario, donde se modifica el modelo de otorga-

1 CASEN es la Encuesta de Caracterización Socioeconómica aplicada por el Ministerio de Desarrollo Social, la cual entrega información relevante que orienta la aplicación de la política pública en Chile. 
Salmonicultura 2.0 en Chile: Una mirada desde la gobernanza ambiental Vallejos-Romero, Arturo; Oyarzún Gutiérrez, Ivone y Garrido Castillo, Jaime

miento y operación de los centros de cultivo; b) Garantías, agilizando el trámite de garantías sobre concesiones y autorizaciones de acuicultura; c) Fiscalización, fortaleciendo las facultades del Servicio Nacional de Pesca, de modo de contar con los instrumentos adecuados para controlar y prevenir eficazmente el cumplimiento de las disposiciones ambientales y sanitarias y d) Patentes, aumentándolas gradualmente a partir del año 2010.

A partir de los cambios realizados, el Banco Central (2011) presentó cifras que exponen que en el último trimestre del 2011 el sector pesca creció un 5,5\%, luego de anotar una expansión del $36,6 \%$. Este crecimiento es resultado de una mayor producción de centros de cultivo de salmones, que contrastó con la caída de la pesca extractiva. Esta producción de centros de cultivo se desempeñó bajo un mayor control del virus ISA, sin embargo, bajo este nuevo marco para la salmonicultura han emanado una serie de conflictos, donde se ha manifestado la poca confiabilidad en sus prácticas productivas por las secuelas de la crisis que aún repercuten en la región y que se ha evidenciado y vuelto a poner en tensión la gestión de la actividad ${ }^{2}$.

En este contexto, el objetivo de la investigación, responde al interés de analizar el nuevo marco de regulación de la salmonicultura (denominada industria del salmón 2.0) y su viabilidad futura, lo cual se observa a través de los lentes de los propios actores del sector. El foco de observación descansa en la percepción y por ende la construcción social que los actores realizan sobre la gestión que se ha venido implementando luego de la crisis del virus ISA. La propuesta conceptual se resuelve en este artículo a través del enfoque de la gobernanza ambiental y metodológicamente a través de un diseño de carácter cualitativo, que releva un conjunto de entrevistas semiestructuradas aplicadas a informantes clave, pertenecientes a distintos ámbitos de actuación del sector salmonideo. La investigación explora en tres ejes fundamentales: la concepción de sustentabilidad, el alcance y transparencia de la información pública, y los espacios de participación.

\section{Gobernanza Ambiental a partir de la crisis gubernamental y ecológica}

Desde una mirada histórica, la sociología ha planteado que la industrialización, especialmente sus factores productivos, han afectado la naturaleza y el orden social, produciendo riesgos y peligros que ha puesto en jaque la vida en general y en particular (Beck, 1998, 2008). El autor expone que tales "riegos se han convertido en el motor de la autopolitización de la so-

2 El Servicio Nacional de Pesca del Gobierno de Chile, confirmó el brote del virus ISA en salmonera de la zona norte de Aysén. El Servicio comunicó que un estudio de secuenciación ratificó que la cepa del virus detectado en una jaula del centro Arbolito, perteneciente a Southern Cross Seafood, corresponde a la variante de ISA HPR 7A, lo cual confirma y reabre la crítica al modelo de gestión que el sector ha implementado en la salmonicultura (La Tercera, 2013). 
ciedad industrial moderna; e incluso más, ha variado el concepto, la localización y los medios de la política" (Beck, 1998: 237). A través de los éxitos de las instituciones de la modernización industrial se suceden una serie de consecuencias tanto ambientales como políticas.

A partir de esta problemática, los gobiernos y las administraciones públicas en Latinoamérica han sido críticos y a la vez criticados, dada la "ineficacia social e ineficiencia económica de los programas de gobierno del Estado Social ${ }^{3 " ;}$ esto se ha agravado y observado como crisis desde finales de la década de 1970. Es así como las reformas institucionales que se llevaron a cabo se establecieron bajo el carácter de una Nueva Gestión Pública (NGP), a la par con una nueva gobernanza que somete al gobierno a un proceso que va más allá de sus acciones, donde deben incluirse actores del ámbito civil y privado en la gestión gubernamental (Aguilar 2010a, 2010b). Estos actores externos se definen como grupos sociales que velan por sus intereses, definen sus propios objetivos de convivencia y participan de diversas maneras en el entramado social. Esta situación promueve la interlocución entre grupos, pero adolecen de un conocimiento e información completa, debido a sus expertices, funciones y roles para lograr sus objetivos.

Este conocimiento parcializado en la ciudadanía y gobiernos da paso a la activación de redes sociales y a una varia- ción de roles en la organización que se adaptan a la naturaleza de los problemas, llevando a una forma descentralizada apoyada en la solidaridad, confianza y cooperación de estos actores en la sociedad. Por lo tanto, la gobernanza tiene como características la horizontalidad en la toma de decisiones, la cooperación entre actores cuyas acciones son interdependientes, y una mayor participación ciudadana, formas que en la práctica son un proceso lento y complejo, y las cuáles conducen a la pregunta de cómo integrar a estos distintos actores que se enmarcan en distintas esferas de la sociedad para tomar decisiones en común (Innerarity, 2011; Aguilar, 2010b).

En el contexto de esta problemática, expresada en la crisis a fines de la década de 1970, Hardin introduce la variable medioambiental, dando a conocer la importancia en torno a que los recursos naturales son de acceso libre (bienes comunes) y no existe incentivo para preservarlos: "la ruina es el destino hacia el cual corren todos los hombres, cada uno buscando su mejor provecho en un mundo que cree en la libertad de los recursos comunes" (Hardin, 1968; 1246). Es decir, resulta difícil no conducir a la sobreexplotación cuando los bienes comunes de libre acceso generan un beneficio individual o privado sobre el dueño, siendo los demás propietarios los que conviven con el costo social y ambiental de la sobreexplotación del dueño.

3 Aguilar (2010a) define el Estado social a grandes rasgos como un Estado de gasto, financieros, fiscal, dado a su pretensión de cubrir las necesidades y expectativas materiales de los ciudadanos. 
Salmonicultura 2.0 en Chile: Una mirada desde la gobernanza ambiental Vallejos-Romero, Arturo; Oyarzún Gutiérrez, Ivone y Garrido Castillo, Jaime

A partir de esta definición de la problemática y precisión de Hardin (1998), no tan sólo existe rivalidad en lo común, sino también el fracaso de la propiedad privada y lo gubernamental como lo explica Ostrom (2000) para quien, es necesario una mayor participación descentralizada por parte de la ciudadanía; esto permitiría resolver de mejor manera estas rivalidades en base a los recursos naturales, "un sistema robusto de gobernanza reconoce el aspecto multiescalar de la gobernanza de los recursos naturales, al igual que la presencia de los incentivos individuales, y busca corregirlos" (Ostrom, 2000:3).

De esta manera, los problemas medioambientales van de la mano con la forma de gobernarlos, no sólo los bienes públicos, sino también los recursos naturales dado su importancia para las futuras generaciones y el planeta. Por lo tanto, en este marco, la gobernanza ambiental entendida como la forma en que actores, mediados por estructuras e instituciones, se relacionan para abordar problemas y desafíos ambientales comunes, y donde estos medios, primero, limitan y/o constriñen la interacción en- tre los seres humanos y las organizaciones de la sociedad con el medio ambiente (Hendricks et al., 2009) y, segundo, si alguno cambia o aumenta sus grados de libertad respecto a los otros, se afecta la dinámica de la gobernanza ambiental.

En este contexto y problemática, el concepto de gobernanza ambiental se asienta en tres componentes fundamentales que son: 1) la sustentabilidad de los recursos naturales, 2) la transparencia de la información pública y su mayor alcance, y 3) un aumento en la participación ciudadana dado la mayor población ciudadana informada. Este tercer componente no tan sólo toma en cuenta los espacios de participación, sino también la fiscalización como control o accountability, es decir, "aun cuando los ciudadanos no están en capacidad de controlar a los gobiernos obligándolos a seguir sus mandatos, podrían ser capaces de hacerlo si pudieran inducir a los gobernantes electos a aceptar que tendrán que dar cuenta de sus acciones pasadas" (Przeworski, 1998: 15).

La gobernanza ambiental puede analizarse gráficamente como lo representa el Diagrama 1:

\section{Diagrama 1 \\ Componentes de la Gobernanza Ambiental}

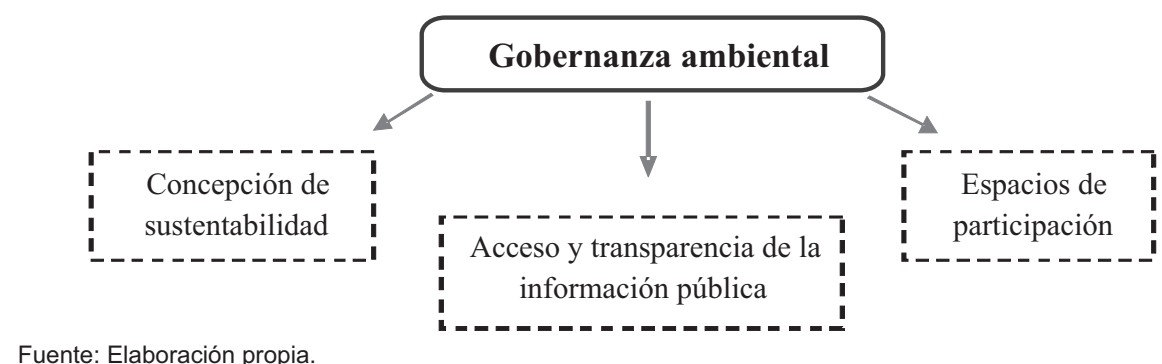

Fuente: Elaboración propia. 


\section{Los actores de la salmonicultura en la región de Los Lagos: el diseño metodológico de la investigación}

Según lo expuesto en los puntos anteriores, el propósito principal de este trabajo apunta a construir un análisis exploratorio de la salmonicultura 2.0, por medio de un acercamiento empírico que releva la significación que establecen los distintos actores vinculados al rubro, en torno a las tres grandes categorías que se desprenden del enfoque de la gobernanza ambiental.

Para ello, la metodología y análisis fueron abordados desde un enfoque cualitativo, con el objetivo de acercarse lo más posible a la comprensión del fenómeno en su totalidad, nunca fragmentado o aislado del contexto (Ruiz, 2007). Adicionalmente, se complementa con datos cuantitativos, los cuales se utilizaron para dar a conocer y contextualizar la problemática en la región de Los Lagos. El estudio tiene como insumo fuentes primarias (actores relevantes del sector de pesca y acuicultura de la Región de Los Lagos) y secundarias (informes, investigaciones y estudios). En ese sentido, además, se resguarda la triangulación de la información y con ello la confiabilidad de la misma (Alvarez-Gayou, 2003; Flick, 2004).

El trabajo de campo se realizó en la ciudad de Puerto Montt-capital regional-, y consistió en la inserción de un investigador (socióloga) por tres meses en vinculación con los distintos sectores que conforman el rubro salmonideo. Una vez identificados los informantes clave se procedió a la aplicación de entrevistas usando pautas semiestructuradas. De este trabajo se obtuvieron notas de campo diarias y 15 entrevistas grabadas. Todo este material se trabajó mediante codificación abierta y axial (Strauss y Corbin, 2003), se utilizó el software ATLAS.ti 7.0, con el propósito de construir mapas conceptuales o redes semánticas.

Cabe mencionar que se optó por la técnica entrevista entendiendo que se trata de un mecanismo efectivo para la transmisión de información, debido a su capacidad para penetrar en el significado subjetivo que los propios entrevistados le otorgan a los fenómenos sociales o situaciones de su propia experiencia, contribuyendo éstas a una "descripción densa". De allí que la entrevista es considerada como un proceso de producción de sentido que se expresa en un discurso, el cual recoge la percepción de relaciones e interacciones que en todas sus dimensiones son el reflejo de una construcción social. En ese marco adquiere relevancia y confiabilidad la valoración e interpretación que los sujetos hacen de las dimensiones consultadas.

Denman y Haro (2000: 32) establecen que el muestreo cualitativo debe obedecer a la "inclusión de representantes de los diferentes estratos o situaciones sociales en que se expresa un fenómeno social". Asumiendo esta premisa, los criterios para la identificación y selección de los actores se sustentaron en la relación y participación con la salmonicultura en la región de Los Lagos, distinguiendo actores provenientes del sector público Unidad Acuicultura del Servicio Nacional de Pesca -SERNAPESCA-, Corporación de Fomento -CORFO-, Servicio de Cooperación Técnica -SERCOTEC-, IV zona de 
Salmonicultura 2.0 en Chile: Una mirada desde la gobernanza ambiental Vallejos-Romero, Arturo; Oyarzún Gutiérrez, Ivone y Garrido Castillo, Jaime

pesca XIV-X Regiones y Ministerio del Medio Ambiente), privado (Empresa Delfish, Pacific Star y Salmones Humboldt) y de la sociedad civil (Consultora Pupelde, Consultora GEQ, Centro I MAR de La Universidad de Los Lagos, Centro CIEN de la Universidad Austral, Confederación Nacional de Pescadores Artesanales de Chile (CONAPACH), Consejo Regional de Pescadores Artesanales de la Región de Los Lagos (COREPA) y la Unión de Federaciones de Pescadores Artesanales).

Los actores privados pertenecen al sector económico, empresas, que están a cargo de las actividades económicas y productivas. En el caso de la salmonicultura, los tipos de industrias del salmón en Chile son elementales para comprender el encadenamiento productivo, las cuales se clasifican de acuerdo a sus capitales (Montero, 2004), habiendo tres tipos: a) de Capitales Extranjeros, que se definen como aquellas empresas de grandes consorcios transnacionales, cuyo volumen de producción anual supera las 25.000 toneladas y el valor de sus exportaciones es superior a 50 millones de dólares; b) Empresas Mixtas, constituidas originalmente por capitales nacionales que alcanzan niveles de producción con estándares nacionales de empresas grandes y medianas. Su producción llega a 20.000 toneladas aproximadamente y sus ventas oscilan entre 15 y 50 millones de dólares; y por último, c) las empresas de Capitales Nacionales, que se definen como empresas de medianos y pequeños estándares internacionales, de origen familiar, de capitales regionales y nacionales y que tienen ventas inferiores a 15 millones de dólares.
Los Actores Públicos son parte del sector público encargado de velar por la implementación y cumplimiento de las políticas públicas en el sector. Las instituciones gubernamentales relacionadas son: a) SERNAPESCA, cuya labor es fiscalizar el cumplimiento de la normativa pesquera y de acuicultura, nacional e internacional, como trabajar por el desarroIlo sustentable del sector pesquero nacional; b) CORFO, que está encargada de impulsar la actividad productiva; c) SERCOTEC, corporación de derecho privado, dependiente del Ministerio de Economía, que promueve y apoya por medio de asesoramiento técnico las iniciativas de mejoramiento de la competitividad de las empresas; d) la Dirección Zonal de Pesca de las regiones XIV-X, las que son reparticiones funcionales de la Subsecretaría de Pesca y donde una de sus líneas es promover el desarrollo sustentable de la actividad pesquera y acuícola; por último, e), la Superintendencia del Ambiente, servicio público descentralizado, que está encargado del seguimiento y fiscalización de las Resoluciones de Calificación Ambiental, de las medidas de los Planes de Prevención y/o de Descontaminación Ambiental.

Los actores de la Sociedad Civil están ligados a organizaciones sociales, quienes contribuyen al desarrollo de la salmonicultura, y a la vez, están dentro del marco de la problemática. Las organizaciones que se identificaron fueron: a) Consultoras, compuesta por expertos en materia de asesoramiento; b) Universidades, que por medio de investigaciones y estudios generan conocimiento en la temática. Se identifican dos universidades en la región de Los Lagos, que traba- 
jan en investigación básica como aplicada ligada a la salmonicultura, estas son la Universidad Austral de Chile y la Universidad de Los Lagos; c) Sindicatos, asociaciones de trabajadores para la defensa y promoción de intereses profesionales, económicos o sociales de sus miembros. En este caso, son organizaciones de pescadores artesanales que se han visto envueltos en el conflicto regional (Figura 1).

\section{Lectura de las percepciones y construcciones de la Salmonicultura 2.0}

Antes de dar a conocer los resultados, es importante visualizar y reafirmar los ejes de estudio que se aplicaron a los entrevistados: la sustentabilidad, el alcance y transparencia de la información pública y los espacios de participación ciudadana, ejes que se descuelgan de los antecedentes teóricos de la gobernanza ambiental. A partir de estos ejes, los resultados son categorías que se consideran relevantes obtenidas de las entrevistas a los actores.

\subsection{Concepción de sustentabilidad}

Según la concepción de sustentabilidad, del análisis de las entrevistas (Diagrama 2) se desprenden dos visiones: la desarrollista y la ambientalista.

En la Visión Desarrollista, los entrevistados tiene una actitud más optimista ante la concepción de sustentabilidad, es decir, se cree que la sustentabilidad va de la mano con la economía y la producción industrial según lo mencionan los estándares internacionales ligados al Desarrollo Sustentable. Los actores exponen que de esta manera se puede lograr la im-

Figura 1. Matriz de Actores

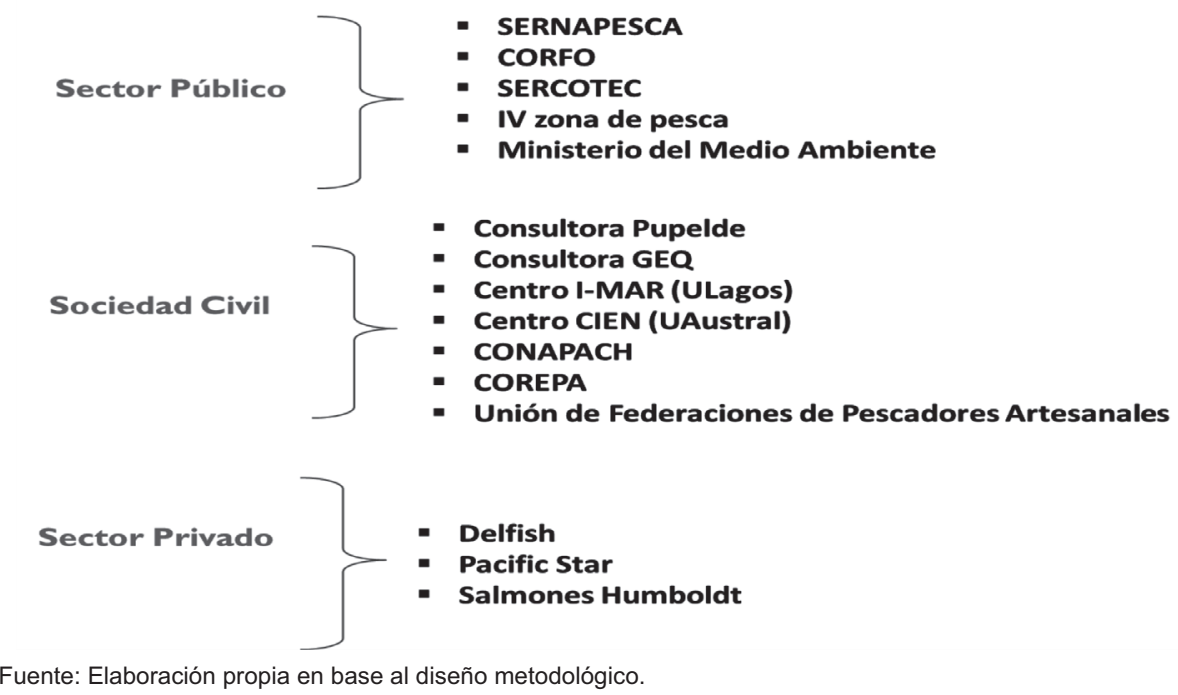




\section{Diagrama 2 \\ Red Semántica de la Sustentabilidad}

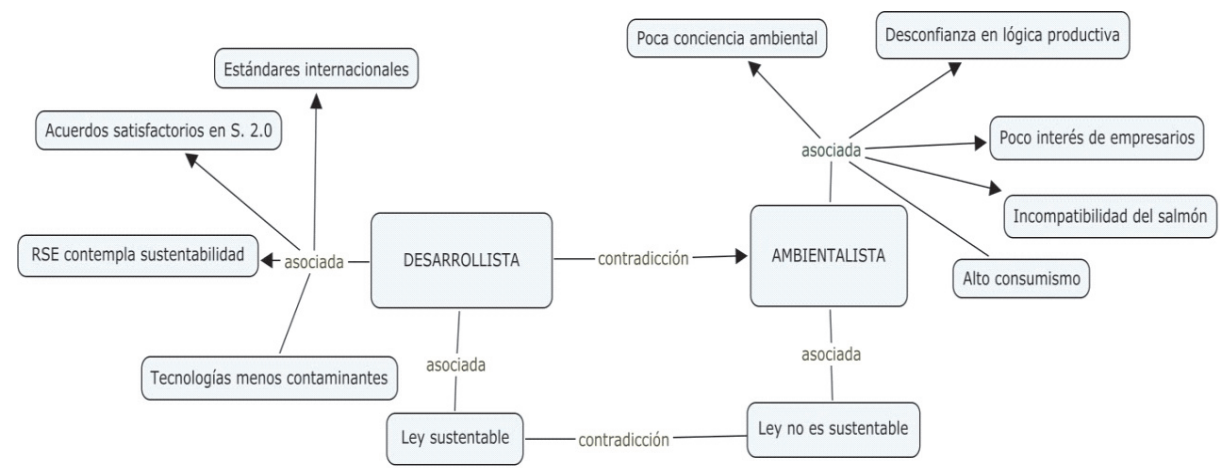

Fuente: Elaboración propia.

plementación de tecnologías que sean menos contaminantes para el medio ambiente, dar cumplimiento de la Nueva Ley de Pesca y Acuicultura 20.434 y llevar a la práctica Responsabilidad Social Empresarial (RSE), en el sentido que se lleve a cabo la labor ambiental (sustentabilidad ambiental) desde las empresas. Aún ante la opinión que los acuerdos de la salmonicultura 2.0 fueron satisfactorios y mancomunados, los actores exponen que en la nueva salmonicultura quienes tienen la misión de efectuar los cambios e iniciativas es el empresariado. Uno de los entrevistados expone lo siguiente:

"Esta salmonicultura 2.0 es una acción mancomunada en que intervienen muchas partes, no es privilegio de una en particular, es decir, no es la acción del empresario individual que genera el concepto de salmonicultura 2.0, sino que aquí hay una intervención, hay una interrelación desde el empresario a nivel local, del empresario con sus contrapartes, con la comunidad, con el sector público que cumplen, que va a cumplir, o que está cumpliendo un rol preponderante súper importante en la sustentabilidad"(Entrevistado 1, Entrevista 2011). En la Visión Ambientalista, los entrevistados proclives a esta visión son pesimista en cuanto a la sustentabilidad del sector salmonero, pues se argumenta que los procesos productivos son intensos y están fuertemente relacionados con el beneficio económico, no siendo esta dinámica compatible con el respaldo y cuidado de los recursos naturales para que prevalezcan en el tiempo y puedan ser utilizadas por las generaciones futuras. Se recalca además que el salmón como especie exótica está en manos de procesos productivos que alteran el medio acuático nativo. Se avala esta visión pesimista por los entrevistados, cuando se argumenta del poco interés y poca consciencia que se ha demostrado en el área, especialmente de quienes están a cargo de la producción de salmones en la región de Los Lagos, lo cual causa desconfianza y sospechas por las consecuencias que tuvo el primer modelo de salmo- 
nicultura y que terminó en la crisis del virus ISA. La consciencia, según los actores, se define a partir de la experiencia, es decir, aquellas personas que han tenido más relación con el mar por años en el transcurso de su vida, saben de mejor manera los cambios y los factores que influyen en las condiciones marítimas, como lo menciona por ejemplo el siguiente entrevistado:

"Para mí la pesca artesanal es una gran empresa que tiene más de 78 mil dueños, porque somos más de 78 mil pescadores artesanales inscritos en SERNAPESCA, y esos 78 mil dueños generan cientos y miles de empleos, y eso para mi es desarrollo sustentable. (...) Las industrias salmoneras crearian en su momento mucho empleo, porque generó mucho empleo, pero el gran error que cometió la industria salmonera fue que se envició con el dinero [y] quiso generar más de lo que pudo hacer" (Entrevistado 2, Entrevista 2011).

\subsection{Acceso y transparencia a la información pública}

La variable acceso y transparencia a la información pública, así como el análisis de las entrevistas, arrojó lo se expresado en el Diagrama 3.

De la información pública, por un lado hay quienes afirman que toda la información está en la web y que esta es transparente, y por otro lado, las instituciones públicas están disponibles para entregar dicha información. Un actor de la sociedad civil lo expresa de la siguiente manera:

“... si tengo acceso a internet puedo ver lo que está pasando con los proyectos en Chile, no hay secreto y la informa-

Diagrama 3

Red Semántica de la Información Pública

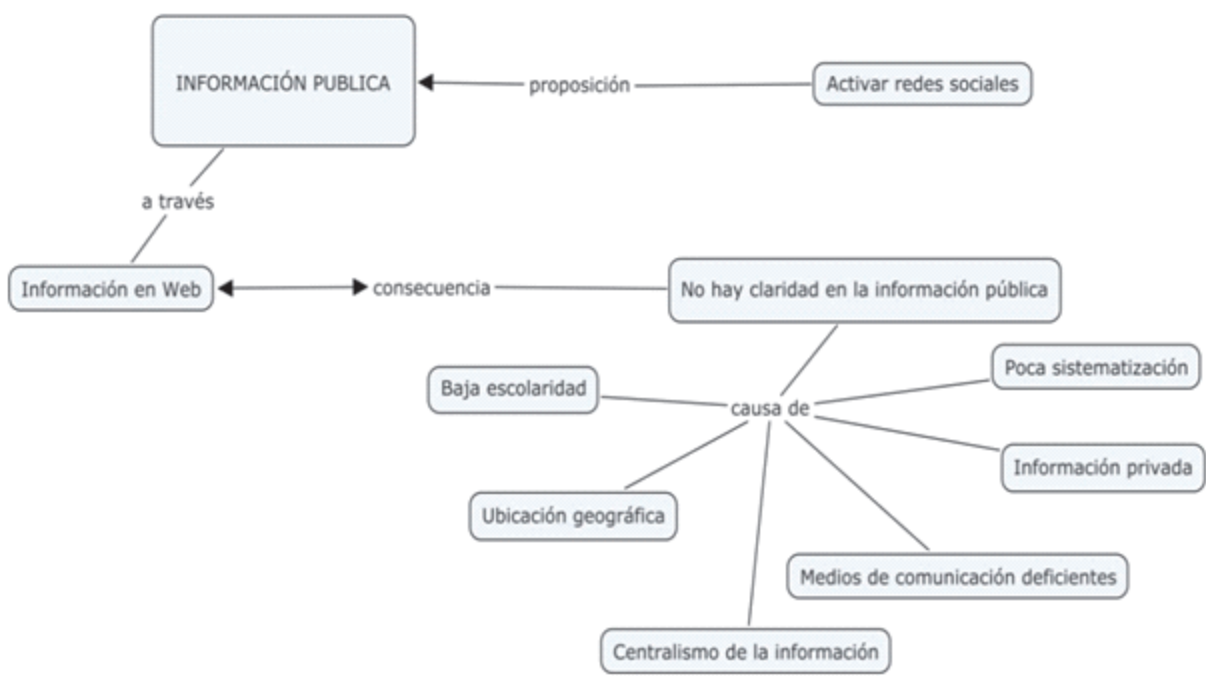

Fuente: Elaboración propia. 
Salmonicultura 2.0 en Chile: Una mirada desde la gobernanza ambiental Vallejos-Romero, Arturo; Oyarzún Gutiérrez, Ivone y Garrido Castillo, Jaime

ción es absolutamente pública, es el sistema de evaluación hasta que yo sé, más transparente del mundo o uno de los más transparentes del mundo" (Entrevistado 3, Entrevista 2011).

Por otro lado, un gran número de entrevistados opina que la información pública no es clara, lo cual afectaría a la transparencia y su acceso (alcance). Esta situación se da en primer lugar por la baja escolaridad, ya que se sostiene que parte de la ciudadanía no tiene la educación suficiente para comprender e interpretar la información, a lo que se suma una información que usa términos muy técnicos y las herramientas para la búsqueda de información no se tienen. Esta categoría se reafirma a través de la siguiente cita:

"Si tú piensas en las personas, en la comunidad, las comunidades indígenas, los vecinos, yo me imagino que ya lograr acceder a un proyecto en particular en la página del sistema de evaluación de impacto ambiental es un desafío y se lo digo por experiencia propia, a mí me pasa todos los días (...) La pregunta es ¿puede todo el mundo con esa facilidad, o dificultad llegar a encontrar un proyecto en particular? , y si lo encuentra ¿va a poder abrir y encontrar como abrir los informes o la información que ellos están buscando?, y una vez que la encuentran, ¿está esa información disponible en un formato en que se pueda comprender?, a veces si, a veces no. Hay distintos niveles de información, unos que son muy crípticos, otros que ni siquiera viene con tablas de interpretación de los resultados y otros que te presentan gráficos, pero la manera en que se presenta la información no está estandarizada"(Entrevistado 4, Entrevista 2011).
De la mano con la baja escolaridad, se encuentra la carencia de sistematización como otra particularidad de la información pública, es decir, ésta no está ordenada para la comprensión de todo ciudadano. Otro problema que surge tiene relación con la ubicación geográfica, pues la región de Los Lagos tiene una gran cantidad de islas interiores, las cuales, se caracterizan por la poca o baja señal de comunicación, la lejanía de las ciudades y las dificultades de transporte, siendo éstas obstaculizadores para requerimientos de la información, afianzando con ello el centralismo de la información pública en las capitales regionales. Los actores evidencian que los medios para comunicar son precarios, ya que sólo se dispone de la web, el diario oficial y escasas veces en radios locales.

De manera complementaria, los actores afirman que toda la información debiese ser pública y no privada, especialmente la información que manejan las empresas. No obstante, a pesar de la gran cantidad de dificultades para acceder a la información pública y la confusión que se genera entre la información en general y la pública, se propone y se tiene más credibilidad en las redes sociales, las cuales observan como un lubricante para la fluidez de la información entre personas, como lo menciona el siguiente entrevistado:

"Hoy día con el acceso a internet, televisión, satélite, telefonía celular, a las redes sociales, el dato, la información, el conocimiento, fluye mucho más de lo que fluía antes, en el espacio y en el tiempo" (Entrevistado 5, Entrevista 2011).

Siendo un medio valorado por los actores, se debe tener precaución con las redes ya que pueden, por un lado, potenciar a 
que la ciudadanía esté bien informada, pero por otro lado, que la ciudadanía sea afectada por la infoxicación (Innerarity, 2010), es decir, por el exceso de información que obstaculiza la información útil.

\subsection{Participación ciudadana}

El segundo eje que se le preguntó a los entrevistados, la participación ciudadana, se divide por un lado en los espacios de participación que perciben los actores, y por otro lado, en la fiscalización como control (Diagrama 4).

En general, se identifican pocos Espacios de Participación y aquellos visualizados son fuertemente criticados. El primer espacio de participación se da a través de los proyectos, siendo de esta manera el sector público quien reconoce la evasión de los proyectos que toman en cuenta la participación ciudadana, esto por la complejidad que reviste su concreción. Por lo tanto, este medio de participación es burocrático y no muy concurrido, según algunos informantes:

"En el tema ambiental, la CONAMA, los proyectos, los sistemas de impacto ambiental, no está la participación ciudadana y muchas veces, muchos proyectos son rechazados a nivel local y de ahí van a nivel central $y$ son aprobados y la opinión de los agentes locales pasa, no cierto, por esto del bienestar del todo el país, el bien común y no local (...), no sé, son cosas que son complejas de resolver pero, de que tiene que haber participación, tiene que haber participación" (Entrevistado 6, Entrevista 2011). El segundo espacio de participación se lleva a cabo a través de las mesas del salmón, las cuales son selectivas al momento de convocar a representantes, produciendo colisiones entre los diversos

\section{Diagrama 4 \\ Red Semántica de la Participación Ciudadana}

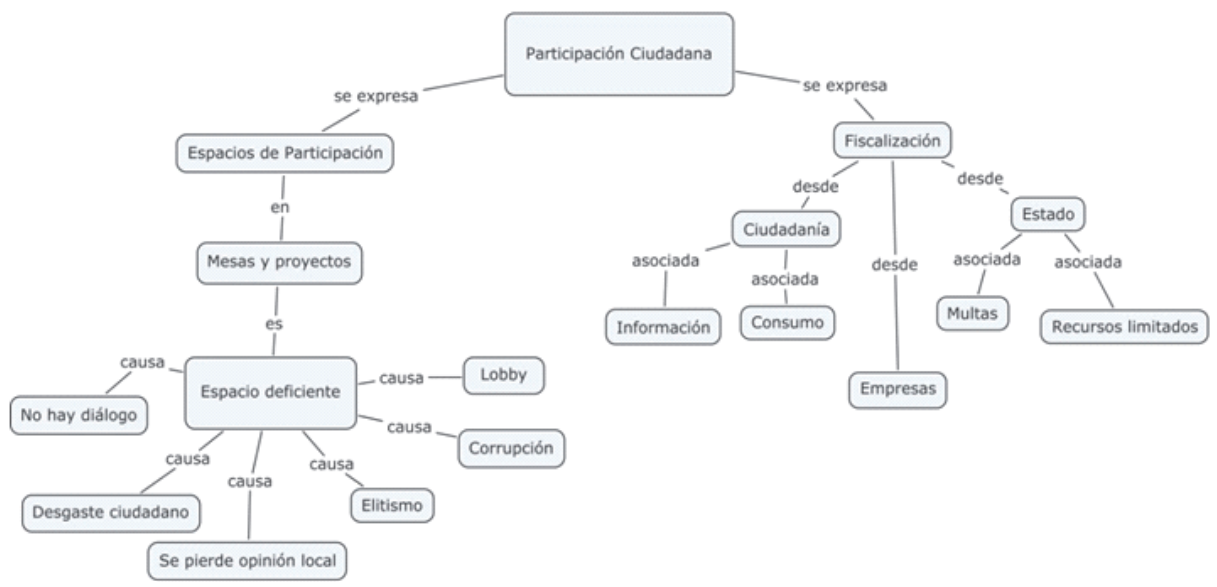

Fuente: Elaboración propia. 
Salmonicultura 2.0 en Chile: Una mirada desde la gobernanza ambiental Vallejos-Romero, Arturo; Oyarzún Gutiérrez, Ivone y Garrido Castillo, Jaime

actores en torno a los acuerdos que se toman, ya que se considera debieran participar personas que trabajan para las empresas salmoneras, que son parte de la cadena productiva, así como las comunidades del borde costero, que son impactadas por centros de cultivo. Así lo indica el siguiente entrevistado:

"Las mesas del salmón tienen su historia en nuestra región, creo que se instalaron tantas mesas que no habían lugares donde guardar información, pero en el fondo las mesas siempre han estado cojas, (...) el tema de la participación no tiene ver con que si yo voy a participary voy a ir siempre en contra del tema, también tiene que ver de cómo acordamos cosas en que todos salgamos beneficiados, pero acá siempre se ha visto el tema de la mesa de cómo le bajamos el perfil, a los temas candentes, en que tiene que ver a quién o a cuál va a perjudicar" (Entrevistado 7, Entrevista 2011). De estos espacios de participación se descuelgan una serie de efectos negativos ocasionados por el insuficiente diálogo, tanto en las mesas del salmón como en los proyectos. Además, el tiempo y la burocracia que conllevan los proyectos desgastan a la ciudadanía, es decir, la jerarquía participativa no permite el empoderamiento ciudadano y a pesar de que la opinión local de las comunidades del borde costero sea importante, porque son los que conviven con los centros de cultivo de salmones, se tiende a perder debido al desgaste ciudadano, pues las opiniones no son tomadas en cuenta en dichos espacios (mesas):

"Hay un poco de participación, pero es participación más bien pública, ahora si esos funcionarios públicos tienen una buena comunicación con las bases sociales y la gente que está ahí podría algún tipo de trabajo, pero desconozco" (Entrevistado 8, Entrevista 2011). Junto a los débiles y escasos espacios de participación, se reconocen fallos de Estado, como la corrupción y el lobby, que complejizan aún más el tema de la participación ciudadana, tanto a nivel regional, como nacional, como lo señala otro de los entrevistados:

"Si yo trabajo para el Gobierno, yo tengo que trabajar para la ciudadanía, no trabajar para una empresa, o no trabajar para una entidad, o no trabajar para mis derechos propios, yo trabajo para la ciudadanía, eso para mí es el Gobierno, pero aquí no se hace eso, aquí la corrupción es muy grande, es muy grande la corrupción" (Entrevistado 2, Entrevista 2011).

Por último, otro efecto de la situación de la participación es la relación entre empresario y trabajador, donde se percibe un fuerte elitismo caracterizados por marcadas diferencias entre éstos, lo cual no permite avanzar hacia un diálogo entre las diferentes realidades que confluyen en una misma actividad. Uno de los entrevistados confirma este punto diciendo:

"Había una empresa salmonera que decía: te desafío a ver que alguien gane menos de 300 mil pesos, vea al junior, el que menos tiene posibilidades de ganar, te aseguro que gana más de 300 mil pesos, y eso es así. $Y$ aquí no se identifican, porque aquí hay una cuestión media elitista, el salmonero es uno solo y el ¿resto los trabajadores? El mejor salmón lo comes en Alemania y no lo comes acá" (Entrevistado 3, Entrevista 2011). 
La Fiscalización se clasifica en tres unidades según los informantes. Primero, la fiscalización desde el Estado, segundo, la fiscalización desde el autocontrol (autorregulaciones), y por último, la fiscalización por parte de la ciudadanía.

En cuanto a la Fiscalización desde el Estado, la actual Ley de Pesca y Acuicultura (Gobierno de Chile, 1991) aumenta la fiscalización por parte de SERNAPESCA. Los actores del sector afirman que los recursos para la fiscalización son limitados, ya que al fiscalizar esta actividad requiere de un control de la gran parte de los centros de cultivo que están en diferentes ubicaciones geográficas de la región, lo cual contempla factores tales como tiempo, clima y transporte, entre otros, que en sí conllevan grandes sumas de dinero público. Sin embargo, también se toma en consideración que si se focalizan estos dineros públicos solamente en fiscalización, se dejan de lado otras actividades con afinidades a la pesca y acuicultura, así como prioridades sociales relacionadas con la salud y la educación. Pero a pesar de que se observa poco probable el llevar a cabo una fiscalización en su totalidad, se propone que las multas son una vía de solución, ya que si estas fueran altas, de tal forma que el empresario se vea en la obligación de tomar medidas sustentables o de lo contrario perder su empresa, se tomaría un mayor peso de la problemática y sus posibles consecuencias, como lo fue con la crisis del ISA. Uno de los entrevistados, por ejemplo menciona:

"Efectivamente se requiere, y siempre se ha requerido, la pesca artesanal por otro lado son veinte mil pescadores artesanales, y para los procesos de fisca- lización que llevaba el servicio en ese tiempo habrán sido cinco o seis funcionarios para toda la región, con dos camionetas, recorrer con no sé cuántos botes costeros. Yo tengo la impresión que de todas maneras ha crecido, al mismo tiempo la dotación y el recurso, pero siempre va desfasado, la industria crece con tal rapidez y hay que pedir limosna a nivel central al servicio nacional de pesca, no tienen ni siquiera una lancha para que se puedan mover" (Entrevistado 9, Entrevista 2011).

La Fiscalización desde autocontrol estaría básicamente destinada al cumplimiento de los deberes y se realizaría desde las mismas industrias ligadas a la salmonicultura, es decir, desde el apoyo, coordinación y control entre industrias, pues serían los más interesados que el medio ambiente esté en condiciones favorables y saludables para la producción:

"Yo creo que cualquier empresa, cuando nacen, son cosas medias extrañas. Todo lo que te piden es un requisito legal, pero después tú te vas dando cuenta, que más que requisito legal es una necesidad que tú tienes que tener, es decir, no es bueno ser sustentable" (Entrevistado 10, Entrevista 2011).

De la Fiscalización desde la ciudadanía, por un lado, se afirma que hay poca información hacia la ciudadanía sobre esta actividad productiva, ya que, por ejemplo, cuando se trata de detener un centro de cultivo se tiene un mes de tiempo para hacer el trámite correspondiente, lo cual puede ser suficiente como insuficiente si no se cuenta con la información necesaria. Se sostiene también que hay un servicio de seguimiento en línea, que es el Servicio de Evaluación Ambiental 
Salmonicultura 2.0 en Chile: Una mirada desde la gobernanza ambiental Vallejos-Romero, Arturo; Oyarzún Gutiérrez, Ivone y Garrido Castillo, Jaime

(SEIA), donde cualquier ciudadano puede acceder a la información de todos los proyectos de evaluación de la actividad, pero el acceso a este portal para la ciudadanía es deficiente, pues significa estar conectado y pendiente la mayor parte del tiempo. Por otro lado, hay un tipo de fiscalización que se respalda a través del consumo de salmón, es decir, si se consume poco de un producto, los niveles de producción tienden a bajar. El problema que tiene este tipo de fiscalización, es que el consumo de Salmón en Chile es bajo, pues la mayor parte es exportado, por lo que un control desde el consumo es poco viable de ser llevada a cabo. Por último, e íntimamente relacionado con los puntos anteriores, como el Salmón es una especie exótica y poco se consume en el país, es una débil fuente de identidad regional. La siguiente cita lo reafirma:

"En la última ley del salmón, lo que propusimos era participar de un consejo donde estén representados artesanales, autoridad marítima, crear una instancia legal que sea la que se encargue por ley de revisar todo este tema y fue rechazado, y eso era una comisión. Era una instancia legal donde estuviera todo el mundo representado, ... y ahí cada declaración ... sea revisada con un poquito más de justicia y eso no se dio" (Entrevistado 11, Entrevista 2011).

\section{La Gobernanza Ambiental y la Salmonicultura $\mathbf{2 . 0}$}

Partiendo de la premisa de que la gobernanza ambiental nace del fracaso previo de una tipo de gobierno vertical, basado en la jerarquía y ligado a las crisis económicas, según los resultados de este caso de estudio exploratorio, se puede constatar que la crisis del virus ISA afectó gravemente la economía regional y que ésta llamó la atención del Estado para su intervención, en tanto apoyo para el resurgimiento de la salmonicultura, como en la fiscalización para mejorar los procesos productivos.

Por lo tanto, si se adaptan los formatos de una Gobernanza al rubro de la salmonicultura, que después de la crisis debió observar tales modelos, en la actualidad los actores siguen percibiendo un formato antiguo de gestión, primero, porque a pesar de que se considera el importante rol del Estado y sus instituciones de servicio público, en la práctica es débil en su gestión y administración por la funcionalidad vertical- burocrática que le caracteriza, lo cual se observa a través de la poca claridad de la información pública y los insuficientes espacios de participación.

Más aún, se le acusa al Estado de fallos, tales como corrupción y lobby, lo cuales dan paso a la desconfianza, baja credibilidad y una deslegitimización de la gestión por parte de la ciudadanía. Por lo tanto, los déficits con los que se encuentra la participación, que se grafican en formatos simples, espacios no vinculantes, excluyentes y corruptos, dan cuenta de la necesidad de pasar a un modelo de gobernanza que propicie y afiance formatos vinculantes, inclusivos, transparentes y de confianza -está relacionada con indicadores subjetivos como la honradez, abogar por el bien común, integridad, entre otros- (Vallejos, 2012), variables importantes y basales en el problema y que la literatura actual pone como relevante a la hora de dar cuanta de los problemas y 
conflictos socioambientales ligados a este caso en específico como a muchos otros (Gamero et al., 2011; Espluga et al., 2009).

La segunda razón por la cual no se puede hablar de un modelo de salmonicultura que tenga en cuenta los principios de la gobernanza ambiental, esenciales y basales en la nueva mirada que se le quiere imprimir a la gestión, es que no se cree que la salmonicultura 2.0 fue y vaya a ser sustentable, dado las falencias de los procesos productivos que llevaron a la crisis del virus ISA, lo cual afectó a gran parte de la región y creó un ambiente de desconfianza en la ciudadanía hacia esta actividad productiva.

Se suma a lo anterior, el reconocimiento por un camino por recorrer en materia acuícola, ya que si se habla de bienes comunes, se podrían focalizar esfuerzos, pero aducen que no hay herramientas para llevar un control o fiscalización de lo que realmente pasa fuera como en fondo del mar y los lagos. Ante tal diagnóstico y examen de la problemática, los actores del sector hacen hincapié en actividades menos contaminantes y que pueden generar ganancias, como por ejemplo, el turismo, la recreación y la pesca artesanal.

El tercer argumento en esta línea de trabajo es la gran cantidad de obstáculos que afecta a la participación ciudadana. Asumiendo que para participar se debe tener alguna información, la información pública disponible es poco clara y poco transparente. Existen algunos sectores que están más informados que otros, en la cual caben las preguntas sobre las formas que toman los modelos de intervención, en torno a qué se comunica (qué se selecciona para comunicar), cómo o por qué medio se comunica o transmite la información (medios de comunicación suficientes), si se comprende realmente lo que se comunica, qué lenguaje se utilizó o cual hubiera sido el más apropiado (nivel de comprensión) y cuál es el alcance (acceso a la información) para que esta información realmente sea aceptada y comprendida por el público.

Así, la fiscalización y sus mermas comunicativas ponen de relieve la dimensión objetiva de la confianza, relevando indicadores como infraestructura, personal, financiamiento, entre otros, como modelos o formas de comunicación que se presentan deficitarios y simples, los cuales no toman en cuenta variables contextuales, identitarias, valóricas y comunitarias. En este punto revisten importancia preguntas que tiendan a enfocar la cantidad de información suficiente para que la ciudadanía este bien informada y cumpla su función, así como los modelos que las empresas privadas y públicas pongan en práctica para una comunicación que cumpla con sus objetivos, es decir, pasen de modelos simples a modelos complejos o reflexivos (Vallejos, 2012). En una sociedad del riesgo como la que describe Beck se necesita visibilizar sus dimensiones sociales y la gobernanza ambiental asumirlas, lo cual permitiría gestionar de mejor manera los riesgos y peligros que trae consigo la actividad salmonidea.

Es también relevante un obstáculo que va de la mano al acceso de la información y que es el factor cultural, ya que como lo mencionaba Dagnino et al (2006), el factor cultural está compuesto de capital social que se entiende como la reciprocidad de la información que, ade- 
Salmonicultura 2.0 en Chile: Una mirada desde la gobernanza ambiental Vallejos-Romero, Arturo; Oyarzún Gutiérrez, Ivone y Garrido Castillo, Jaime

más, requiere de confianza y frecuencia en las relaciones entre un grupo de personas. Sin embargo, este factor cultural se ve perjudicado por la distancia (dificultad geográfica) que no permite la organización, la denuncia y la propuesta.

De esta manera, no se puede hablar de una gobernanza ambiental en la región, pero sí a través de los actores se pueden visualizar deficiencias y contradicciones respecto al nuevo formato que ha tomado la salmonicultura 2.0, lo cual permite mirar con mayor detalle la problemática y avanzar hacia una gobernanza ambiental en la Salmonicultura que permita cumplir los objetivos que se ha propuesto.

\section{Reflexiones finales}

Para finalizar, los resultados y la discusión que se ha dado en las páginas precedentes, se asientan en que a partir de las percepciones de los actores vinculadas a la actividad, el espíritu que mueve la nueva forma dada a la salmonicultura no estaría haciendo suyos los lineamientos de la gobernanza ambiental, por lo que este nuevo modelo podría fracasar. Es decir, no se percibe el principio de sustentabilidad en la salmonicultura 2.0 debido a su lenta recuperación ambiental y su actual priorización económica y social. Por otra parte, el alcance de la información pública no es amplio ni efectivo, lo que perjudicaría a la ciudadanía en el conocimiento de sus derechos y de las políticas públicas, generando altos grados de desconfianza y baja credibilidad en el nuevo modelo. Por consiguiente, debido al limitado alcance de la información pública, los espacios de participación también se hacen escasos.

Ante lo expresado, se muestra relevante el tema de la información pública, siendo este un punto neurálgico a trabajar, ya que si no hay estrategias, modelos y redes que permitan dar una información pública de calidad (modelos y estrategias de comunicación), difícilmente podrá existir una fiscalización, sanción y/o propuestas por parte de la ciudadanía, del Estado y desde las mismas empresas en conjunto. Es fundamental entonces, que haya una información clara y precisa, de mayor acceso y sistematizada, que logre abarcar la comprensión de más ciudadanos, y de esta manera poder entablar diálogo para que la toma de decisiones camine hacia la horizontalidad.

Siendo lo anterior de vital relevancia, las acciones debieran tender a propiciar modelos de comunicación que de forma reflexiva e iterativa tomen en cuenta a la diversidad de actores, en el sentido de tomar en serio sus formas que tienen de construir y configurar su actividad (económicamente, culturalmente, ambientalmente, etc.), para que lo que se informe haga sentido y lleve a la transformación que se desea, todo lo cual debiera estar fortalecido por nichos de confianza que permitan legitimar esta nueva forma de gestión, comunicación, participación y fiscalización. En otras palabras, tender a un modelo 2.0 podría allegarnos una gobernanza socioambiental de la salmonicultura en Chile. 


\section{Referencias Bibliográficas}

Aguilar Villanueva, Luis (2010a). "El futuro de la gestión pública y la gobernanza después de la crisis". Frontera Norte, Vol. 22, N 43, pp. 187-213.

Aguilar Villanueva, Luis (2010b). Gobernanza: El nuevo proceso de Gobernar. Fundación Friedrich Naumann para la Libertad, Ciudad de México.

Alvarez-Gayou, Juan Luis (2009). Cómo hacer investigación cualitativa. Fundamentos y metodología. Reimpresión, Paidós, Ecuador.

Banco Central (2011). Cuentas Nacional del segundo trimestre 2011. [Disponible en: Http:/www.bcentral.cl/estadisticas-economicas/publicaciones-estadisticas/trimestrales/pdf/CuentasNacionales_segundo_trimestre2011.pdf (Consultado el 20 de noviembre de 2011).

Beck, Ulrich (2008). La sociedad del riesgo mundial. En busca de la seguridad perdida. Editorial Paidós, Barcelona.

Beck, Ulrich (1998). La sociedad del riesgo: hacía una nueva modernidad. Ediciones Paidós Ibérica, S.A., Barcelona.

Carreño, Arturo (2010). Impactos del virus ISA en Chile. ADCE $N^{\circ} 55$, Fundación Terram, Santiago de Chile.

Centro de Estudios Miguel Enríquez (2007). Chile: La voracidad de los empresarios salmoneros, Santiago: dossier.

Claude, Marcel y Oporto, Jorge (Editores) (2000). La ineficiencia de la Salmonicultura en Chile: Aspectos sociales, económicos y ambientales. Fundación Terram, Santiago de Chile.

Congreso Nacional de Chile (2010). Historia de la ley 20.434, modifica la ley de pesca y acuicultura en materia de acuicultura. Diario Oficial 08 de abril de 2010.
Dagnino, Evelina Olvera, Alberto y Panchifi, Aldo (2006). "Para la otra lectura de la disputa por la construcción democrática en América Latina". Cuadernos para la democratización, CIESAS/ Universidad Veracruzana, México.

Denman, Catalina y Haro, Jesús (Comp.) (2000). Por los rincones. Antología de métodos cualitativos en la investigación social. El Colegio de Sonora, México.

Espluga, Josep; Prades, Ana; Gamero, Nuria y Solá, Rosario (2009). "El papel de la confianza en los conflictos socioambientales". Política y Sociedad, Vol. 42, N² 2, pp. 255-273.

Espluga, Josep; Prades, Ana y Gonzalo, Jan (2010). "Comunicating at the edge: Risk Communication Processes and Structural conflicts in highly industrialized petrochemical areas". Catalan Journal of communication \& Cultural Studies, Vol. 2I, N2 2, pp. 231-251.

Flick, Uwe (2004). Introducción a la investigación cualitativa. Morata, España.

Furci, Giulana (2008). Crisis en la Salmonicultura. Fundación TERRAM, Santiago de Chile. [Disponible en: http://www. Olach.cl/images/minutas/minuta-crisis-salmonicultura.pdf] (Consultado el 20 de Diciembre de 2011).

Gamero, Nuria, Espluga, Josep, Prades, Ana, Oltra, Cristian, Solá, Rosario y Farré, Jordi (2011). "Institutional dimensions underlying public trust in information on technological risk". Journal of Risk Research, Vol. 14, № 6, 2011, pp. 685-702.

Gobierno de Chile (1991). Ley General de Pesca y Acuicultura. [Disponible en: http://www.leychile.cl/Navegar?id Norma $=30265$ ]. (Consultado el 22 de Enero de 2013).

Hardin, Garret (1968). "The Tragedy of Commons". Science, Vol. 162, pp. 12431248. 
Salmonicultura 2.0 en Chile: Una mirada desde la gobernanza ambiental Vallejos-Romero, Arturo; Oyarzún Gutiérrez, Ivone y Garrido Castillo, Jaime

Hendrics, Paul, Betsill, Michele, Cheng, Tony y Pete Taylor (2009). The Landscape of Environmental Governance Reserach. Environmental Governance Working Group, Discussion Paper. [Disponible en http://egwg.colostate.edu/docs/The_Landscape_of_Environmental_Governance_Research. pdf] (Consultado el 21 de Diciembre de 2011).

Igor, Patricio y Díaz, Isabel (2007). Radiografía a la industria del salmón en Chile, bajo la mirada de estándares de RSE. Ecoceanos, Santiago de Chile.

Innerarity, Daniel (2011). ¿Qué es eso de la Gobernanza. [Disponible en: http:// www.globernance.com/wp-content/ uploads/2011/01/Gobernanza.pdf]. (Consultado el 15 de Enero de 2012)

Innerarity, Daniel (2010). "Incertesa i creativitat. Educar per a la societat del coneixement". Debats d'educació, $N^{\circ} 18$, Barcelona.

La Tercera (2013). Sernapesca confirma brote de virus isa en salmonera de la zona norte de Aysen. [Disponible en: http:// www.latercera.com/noticia/negocios/ 2013/12/655-554760-9-sernapescaconfirma-brote-de-virus-isa-en-salmo nera-de-la-zona-norte-de-aysen.html ] (Consultado el 04 de Diciembre de 2013)

Montero, Cecilia (2004). Formación y desarrollo de un cluster globalizado: el caso de la industria del salmón en Chile. Serie N 145, Comisión Económica para América y el Caribe, Santiago de Chile.

Ostrom, Elinor (2000). El Gobierno de los bienes comunes: La evolución de las instituciones de acción colectiva. Universidad Autónoma de México, México.

Pinto, Francisco (2008). La salmonicultura bajo el prisma de la sustentabili- dad. Fundación Terram, APP Serie. $\mathrm{N}^{\circ} 45$, Santiago de Chile.

Pinto, Francisco (2007). Revisión del informe sobre los impactos de la salmonicultura preparado por la Comisión de Pesca y Acuicultura. APP $N^{\circ} 40$, Fundación Terram, Santiago de Chile.

Przeworski, Adam (1998). "Democracia y representación". Revista del CLAD, N ${ }^{\circ}$ 10, pp. 7-32.

Ruiz Olabuénaga, José (2007). Metodología de la investigación cualitativa. $4^{a}$ ed., Universidad de Deusto, Bilbao, España.

Strauss, Anselm y Corbin, Juliet (2003). Bases de la investigación cualitativa. Técnicas y procedimientos para desarrollar la teoría fundamentada. Editorial Universidad de Antioquia, Medellín.

Vallejos, Arturo (2012). "La relevancia de la confianza institucional y la comunicación en la percepción y construcción social de riesgos". Perfiles Latinoamericanos, $\mathrm{N}^{\circ} 30$, Enero - Junio, pp. 151-176.

\section{Entrevistas}

Arteaga, Raúl. Director Ejecutivo consultora GEQ; Puerto Varas 12 de septiembre de 2011.

Brunetti, Pedro. Director Dirección Zonal de Pesca XIV-X Regiones; Puerto Montt 22 de septiembre de 2011.

Buschman, Alejandro. Director Centro I MAR Universidad de Los Lagos; Puerto Montt 21 de septiembre de 2011.

Bustamante, Zoila. Presidenta Confederación Nacional de Pescadores Artesanales de Chile (CONAPACH); Caleta Estaquilla 10 de septiembre de 2011.

Bustos, Jorge. Presidente Consejo Regional de Pescadores Artesanales (COREPA); Puerto Montt 25 de octubre de 2011. 
Escobar, Hugo. Subdirector Regional de CORFO; Puerto Montt 22 de septiembre de 2011.

Ojeda, Pedro. Presidente Unión de Federaciones de Pescadores Artesanales; Puerto Montt 22 de septiembre de 2011.

Salas, Mauricio. Ejecutivo de Fomento Dirección Región de Los Lagos Servicio de Cooperación Técnica (SERCOTEC); Puerto Montt 12 de octubre de 2011.
Santa Cruz, Samuel. Director empresa de Salmones Humboldt; Puerto Montt 13 de septiembre de 2011.

Silva, Enrique. Gerente Empresa de ahumados Delfish; Puerto Montt 10 de octubre de 2011.

Villalobos, Sibel. Encargada de Sección de Política y Regulación Ambiental del Ministerio del Medio Ambiente, SEREMI del Medio Ambiente Región de Los Lagos; Puerto Montt 15 de septiembre de 2011. 